
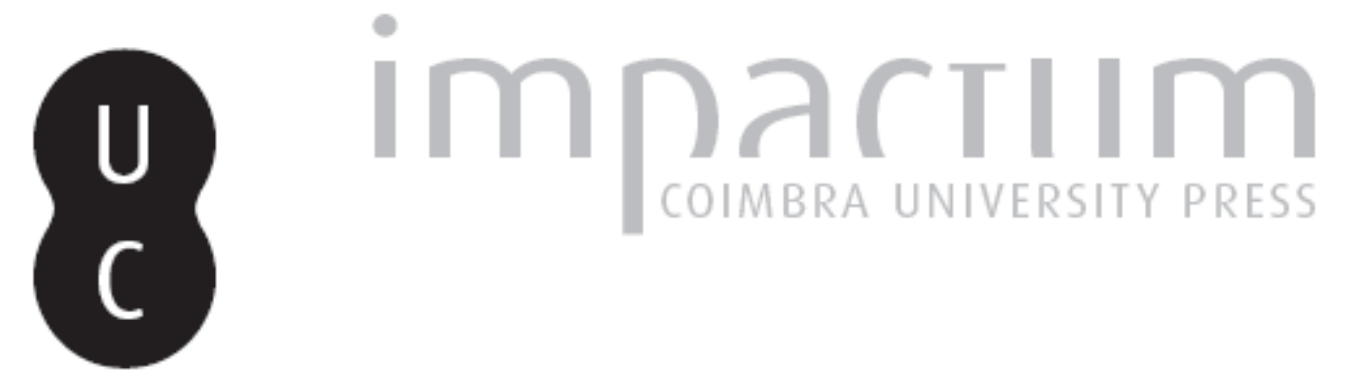

\title{
Para uma epistemologia da arqueologia
}

Autor(es): $\quad$ Alarcão, Jorge de

Publicado por: Imprensa da Universidade de Coimbra

URL persistente:

URI:http://hdl.handle.net/10316.2/45459

DOI:

DOI:https://dx.doi.org/10.14195/1647-8657_34_1

Accessed : $\quad$ 26-Apr-2023 09:53:46

A navegação consulta e descarregamento dos títulos inseridos nas Bibliotecas Digitais UC Digitalis, UC Pombalina e UC Impactum, pressupõem a aceitação plena e sem reservas dos Termos e Condições de Uso destas Bibliotecas Digitais, disponíveis em https://digitalis.uc.pt/pt-pt/termos.

Conforme exposto nos referidos Termos e Condições de Uso, o descarregamento de títulos de acesso restrito requer uma licença válida de autorização devendo o utilizador aceder ao(s) documento(s) a partir de um endereço de IP da instituição detentora da supramencionada licença.

Ao utilizador é apenas permitido o descarregamento para uso pessoal, pelo que o emprego do(s) título(s) descarregado(s) para outro fim, designadamente comercial, carece de autorização do respetivo autor ou editor da obra.

Na medida em que todas as obras da UC Digitalis se encontram protegidas pelo Código do Direito de Autor e Direitos Conexos e demais legislação aplicável, toda a cópia, parcial ou total, deste documento, nos casos em que é legalmente admitida, deverá conter ou fazer-se acompanhar por este aviso. 
UNIVERSIDADE DE COIMBRA

FACULDADE DE LETRAS

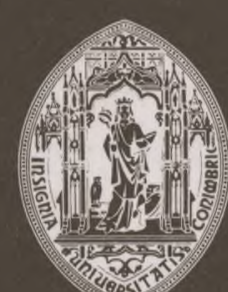

CONIMBRIGA

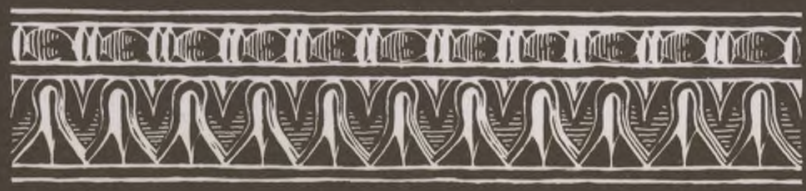

VOLUME XXXIV - 1995

INSTITUTO DE ARQUEOLOGIA 
JoRGE DE AlARCÃo

Professor da Faculdade de Letras de Coimbra

\section{PARA UMA EPISTEMOLOGIA DA ARQUEOLOGIA}

«Conimbriga» XXXIV (1995), p. 5-32

RESUMO: O autor começa por discutir o problema da existência de leis ou regularidades transculturais na Arqueologia. Analisando o trabalho do arqueólogo, distingue e caracteriza os seguintes momentos: interpretação, inferência, classificação e explicação. Defende a manutenção do conceito arqueológico de "cultura" por entender que não foi ainda proposto outro mais operacional. Diminui a importância da teoria no estabelecimento dos factos e considera que esta intervem sobretudo no campo da explicação.

SUMMARY: The author considers the theoretical debate about the formulation of laws or cross-cultural generalisations in archaeology. Examining the epistemology of the archaeological discourse, he distinguishes interpretation, deduction, classification and explanation. He advocates to maintain the archaeological concept of culture. Other concepts, such as horizon or configuration are examined, but that of culture is proposed as still best suited for the elaboration of archaeological discourse. The idea that data are theory-laden is criticized as maximalist epistemological position; theory is conceived as only involved in the explanation of facts, despite the historicity of all forms of interpretation and classification.

Conimbriga, 34 (1995), 5-32 
(Página deixada propositadamente em branco) 


\section{PARA UMA EPISTEMOLOGIA DA ARQUEOLOGIA}

As duas correntes mais influentes da Arqueologia contemporânea, a Nova Arqueologia e a Arqueologia contextuai, a primeira surgida, na década de 60, nos Estados Unidos da América e a segunda, na década de 80, na Inglaterra, reclamam-se de diferentes hermenêuticas. Binford, o fundador da Nova Arqueologia, adopta o modelo hempeliano. Hodder, o arauto da Arqueologia contextuai, confessa-se devedor de Collingwood e, através dele, de Dilthey; poderia citar igualmente Raymond Aron e Henri Marrou.

Hempel constroi a explicação em história sobre o modelo da explicação nas ciências da natureza, num influente artigo sobre $A$ função de leis gerais em História, publicado em 1942 e traduzido para português em 1969 (HEMPEL, 1969: 421-435).

Em história há causas, efeitos e leis. "A explicação histórica, diz Hempel (1969: 426), tem em vista mostrar que o evento em causa não foi «uma questão de acaso», mas era de esperar em virtude de certos antecedentes ou condições simultâneas. A expectativa referida não é profecia nem adivinhação, antes antecipação científica racional que se baseia na admissão de leis gerais".

Pode parecer que a perspectiva hempeliana esquece a intenção e a vontade do sujeito histórico, pelas quais se introduz o indeterminismo dos efeitos. Na realidade, Hempel não deixa de chamar a atenção para o facto de as hipóteses universais (termo que usa como sinónimo de lei) dizerem frequentemente respeito à psicologia individual ou social (1969: 427); não parece, pois, totalmente indiferente ao fenómeno da compreensão, se bem que diga que a sua tese "está em contraste flagrante com a ideia comum de que, em história, a explicação genuína se obtem através de um método que característicamente distingue as

Conimbriga, 34 (1995), 5-32 
ciências sociais das naturais, ou seja, o método da compreensão empatética" (1969: 431, itálicos no original). Este método da compreensão é, para Hempel, apenas um estratagema heurístico que pode conduzir à generalização sob a forma de leis.

Por outro lado, Hempel define as leis históricas não como leis deterministas gerais, isto é, leis sob a forma de condições universais, mas como leis de probabilidade. Na maior parte dos casos, ainda segundo Hempel, as leis que se invocam em história são antes "esboços" de leis, na medida em que sugerem, mas não demonstram, que são de facto relevantes as causas definidas.

Ricoeur afasta, talvez de forma demasiadamente sumária, a interpretação de Hempel, "condenado a nunca atingir o trabalho original e específico do historiador e a impor-lhe um esquema artificial que só satisfaz o epistemologo"; e acrescenta: "o modelo hempeliano dificilmente dá conta do trabalho efectivo do historiador" (1986: 179-180). Ainda na linha de Dilthey, que aprofunda e renova, Ricoeur diz que a história se faz compreendendo e explicando, sem que a explicação tenha a ver com leis.

A compreensão, num sentido amplo, é a percepção de uma subjectividade alheia, isto é, das intenções e dos sentimentos do outro. Ricouer distingue a percepção imediata ou espontânea dessas intenções e desses sentimentos, percepção à qual reserva o nome de compreensão, da percepção analítica. Toda a compreensão implica sinais, que são interpretados. A cólera do outro, compreendo-a eu através dos gestos que o outro faz, da sua ruborização, do seu discurso exaltado e cheio de invectivas. Mas, apesar de a percepção da cólera do outro se fazer a partir de sinais, não preciso de raciocinar sobre eles: a percepção é imediata ou espontânea. Ela é, na expressão de Ricouer, o "momento não metódico" da interpretação. Nem sempre, porém, as intenções são ¡mediatamente aparentes: às vezes requerem análise, dedução, comparação de sinais, exame das circunstâncias. E este o "momento metódico" da interpretação, a que Ricoeur chama explicação. Talvez, no caso de o outro ser uma personagem histórica, a compreensão seja sempre analítica ou, por outras palavras, requeira sempre o tal momento metódico.

Em 51 a.C., Júlio César, procônsul da Gália, solicita que lhe seja prorrogado o proconsulado, que terminava em 1.3.49, até 31.12.49; e solicita mais: que lhe seja autorizado apresentar-se às eleições de Julho de 49 para o consulado, estando todavia ausente de Roma. Que intenções tinha César?

Conimbriga, 34 (1995), 5-32 
Uma parece evidente: a de continuar e consolidar a conquista da Gália. Mas o problema é mais complexo, e não podemos compreender o pedido de César sem pensarmos na ameaça que Catão vinha lançando de o chamar a tribunal por irregularidades cometidas durante o primeiro consulado assim que terminasse a imunidade proconsular. Como procônsul, César era imune. Se terminasse o proconsulado em 1.3.49, poderia ser perseguido. Se o seu mandato fosse prorrogado até 31.12.49, e se fosse eleito como cônsul em Julho de 49, César passaria sem interrupção do proconsulado ao consulado, isto é, de uma imunidade a outra, e não poderia ser perseguido.

A compreensão das intenções de Júlio César passou por uma análise, que envolveu até o exame das instituições jurídico-políticas da República romana, neste caso, o da imunidade governamental: as intenções de César foram explicadas; não podiam ser imediata ou espontaneamente percebidas.

A explicação, em história, segundo Ricoeur, não consiste em mostrar que os factos obedecem a leis, mas em entender analiticamente as intenções dos actores. "A explicação é o que permite seguir, de novo, a história, quando a compreensão espontânea é bloqueada" (RICOEUR, 1986: 182). A explicação vem naturalmente prolongar a compreensão.

A história é uma narrativa de factos cuja relação é contingente, isto é, factos que não se podem deduzir uns dos outros segundo uma relação necessária. Do facto de Caio ter feito isto neste momento não se pode deduzir que fará aquilo no momento subsequente. Luís XVI, em 1789, reconheceu a ruptura financeira do Estado e convocou, para discutir o problema, os Estados Gerais. A reunião dos Estados Gerais não é um facto que se possa deduzir da bancarrota. Luís XVI poderia ter adoptado outras soluções, por exemplo, poderia ter decidido unilateralmente aumentar os impostos.

A função dos historiadores consiste em explicar o porquê. Porque é que Luís XVI tomou a decisão que tomou? E talvez o porquê se encontre quando se pode definir o leque de soluções ou de decisões que se ofereciam ao sujeito histórico, ponderar os pro e os contra das várias decisões e mostrar que aquela pela qual o sujeito optou foi, por tais e tais razões, considerada pelo sujeito como a mais conveniente.

A história não se pode fazer sem desvendar as intenções. A apreensão imediata das intenções é a compreensão; a apreensão analítica é a explicação.

Conimbriga, 34 (1995), 5-32 
Será que a hermenêutica de Ricoeur dá conta do trabalho do historiador mais adequadamente que a teoria de Hempel? Até certo ponto, sem dúvida. A preocupação de encontrar uma unidade profunda entre a narrativa literária e a narrativa histórica levou Ricoeur, porém, a considerar apenas uma forma de história: a história dos eventos. Será que a história económica e a história social se constroem inteiramente sem leis e apenas desenvolvendo analiticamente a compreensão? Será que a explicação, em história, é apenas esse momento metódico que desenvolve analiticamente a compreensão? Não será outra coisa? Será o termo «explicação» unívoco? Terá diversos sentidos?

Deixamos as perguntas aos historiadores. Aqui, queremos abordar o problema em Arqueologia. Até que ponto podemos, em Arqueologia, aceder a intenções e sentimentos? Formulamos ou não leis?

Consideremos, em primeiro lugar, esta segunda questão.

A Nova Arqueologia tem uma declarada intenção nomotética, isto é, de produzir leis. Watson, LeBlanc e Redman afirmam: "O que distingue a arqueologia científica é a sua consciência de que deve formular e comprovar leis hipotéticas gerais" (WATSON, LEBLANC e REDMAN, 1987: 25).

Na realidade, a Nova Arqueologia poucas leis produziu, e mesmo essas tão simples que Courbin lhes chamou lapalissadas desoladoras (Courbin, 1982: 81) e Flannery as apelidou de leis de Mickey Mouse (FlanNERY, 1973, citado por HODDER, 1992: 100). Dunnell, por seu lado, escreveu: "O objectivo principal..., o estabelecimento de leis que relacionem o comportamento com a cultura material, não foi atingido, na melhor das hipóteses, senão de forma rudimentar. Podemos seriamente duvidar que possa ser de qualquer forma atingido" (DuNNELL, 1980: 471).

Apesar destas críticas, cremos que o arqueólogo aplica efectivamente leis que, de forma menos pretenciosa, se poderiam chamar regularidades transculturais, isto é, regularidades que transcendem os sistemas socioculturais particulares e se aplicam a todas as unidades sociais, em qualquer tempo ou espaço.

É conhecida a voga que hoje tem, em Arqueologia, a análise dos territórios de exploração ( Site catchment analysis). A análise parte deste princípio: os habitantes de uma aldeia, dedicados à actividade agropastoril, exploram o território envolvente até ao máximo de uma hora de marcha; a exploração de campos mais distantes não é economicamente viável, porque se perderia demasiado tempo na deslocação.

Conimbriga, 34 (1995), 5-32 
Não é isto uma lei ou regularidade transcultural? Não inventada ou descoberta pela Arqueologia, é certo, mas pela Geografia e adoptada por aquela.

Um sistema de povoados situados numa zona ecologicamente diversificada tende a especializar-se, cada povoado na sua produção, e daí surge, naturalmente, um sistema de trocas. Não é isto outra regularidade transcultural?

Um bando de caçadores/recolectores tende a concentrar-se naquelas épocas do ano em que os recursos são abundantes e a dispersar-se, cindindo-se em unidades menores, eventualmente unifamiliares, nas épocas do ano em que os recursos escasseiam. Não é isto uma regularidade transcultural, desta vez derivada da Antropologia cultural?

Poderíamos citar mais casos. Bastam estes para exemplificar que o arqueólogo recorre efectivamente a generalizações similares a leis para explicar o registo arqueológico.

Nem todos os comportamentos, porém, se podem explicar por leis.

Em Lepenski Vir (Sérvia), entre 5400 e 4700 a.C., homens e mulheres adultos (mais raramente crianças) eram enterrados no interior das casas (HODDER, 1990: 25). Como explicar este comportamento? Não há lei que possa invocar-se. Mas talvez o comportamento se possa entender. Uma das conquistas espirituais do Neolítico terá sido aquilo que podemos chamar a domesticação do medo da morte. Este medo da morte ou dos mortos terá levado os homens, num primeiro momento, a desfazerem-se dos cadáveres em lugares que não frequentavam. Mas em Lepenski Vir os vivos conviviam com os mortos. A morte estava sempre presente e não era coisa que devesse esquecer-se. $O$ facto não se explica por uma lei, mas compreende-se.

Nem todo o trabalho do arqueólogo se efectúa, porém, em termos de compreensão de ideias ou sentimentos ou da aplicação de regularidades transculturais. Vejamos como é que o arqueólogo pratica o seu ofício e consideremos, sucessivamente, a interpretação, a inferência, a classificação e a explicação.

\section{A interpretação}

A interpretação em Arqueologia é uma ultrapassagem da aparência fenomenal da coisa em direç̧ão ao ser da coisa. A interpretação responde à pergunta: o que é isto?

Conimbriga, 34 (1995), 5-32 
O arqueólogo descobre manchas circulares de cor negra no solo e infere dai que está em presença duma cabana pré-histórica; mas, para fazer essa inferência, teve de interpretar primeiro as manchas como vestígios dos prumos ou espeques que constituíam a armação de uma cabana. Teve de perguntar: o que são estas manchas?

As manchas são a coisa, que se pode observar e descrever mesmo antes de entender: são pequenas fossas de um certo contorno, certa dimensão, certa profundidade, cheias de uma certa terra. Mas o que são? Podem ser as covas em que se encaixaram os prumos de madeira de uma cabana, ou covas para plantio de arbustos, ou qualquer outra coisa ainda. Interpretar as covas é definir o que são (ou o que foram).

$\mathrm{O} \quad$ arqueólogo escava uma pequena área quadrangular de tijoleiras dispostas horizontalmente, enquadradas por outras tijoleiras dispostas na vertical. Que são essas tijoleiras? São uma lareira. Mais uma vez temos aqui a definição do ser da coisa, que constitui o momento interpretativo.

Muitas vezes, o ser da coisa é-nos revelado de imediato e sem problemas. O que é esta fossa rectangular, definida por lajes verticais, e no interior da qual se encontram alguns ossos e vasos? É uma sepultura. Tão imediata é a apreensão do ser da coisa que não temos consciência de que estamos a interpretar. Mas basta pensar nas interpretações que se deram às antas ou dólmenes ou aos machados de pedra polida, para tomarmos consciência de como a interpretação é um momento essencial do raciocínio arqueológico e de como esse raciocínio pode conduzir ao erro ou à verdade.

O momento interpretativo está aí, a exigir todas as nossas faculdades de discernimento, quando encontramos um objecto ou uma estrutura que não sabemos para que serve. A coisa comparece como coisa sem sentido, como objecto que se percepciona mas que nós não sabemos ainda o que é, e a interpretação é tanto mais difícil quanto maior for a distância cultural que nos separa daqueles homens que fabricaram e usaram o objecto ou a estrutura.

Em Toothsome, no Illinois, Binford escavou quinze fossas cheias de carolos de milho e de outros elementos vegetais carbonizados. O significado das fossas não era evidente. Binford interpretou-as como estruturas destinadas à combustão de um material que produziria muitos fumos; chamou-lhes, pois, smudge pits, fossas fumacentas. Admitiu, primeiro, que as fossas se destinavam a provocar fumos que afastariam os mosquitos; e mais tarde, revendo a sua interpretação, considerou-as como estruturas para curtir peles, através do fumo (BINFORD,

Conimbriga, 34 (1995), 5-32 
1972: 33-51). Temos aqui a percepção de estruturas cujo significado se apresenta, à partida, obscuro.

É exactamente nesta experiência do desconhecido, daquilo que não sabemos o que é, que se revela a diferença entre a percepção do objecto arqueológico e a percepção do mundo em que vivemos. $\mathrm{Na}$ nossa percepção do mundo, "o conhecimento e a acção não passam de duas faces abstractas de uma relação original e concreta" (SARTRE, 1993: 317). Essa relação não existe na percepção dos objectos arqueológicos, que são objectos de que nos não servimos, e dos quais até podemos ignorar para que é que serviram. A percepção arqueológica não é, como a percepção ordinária do nosso mundo, "un accouplement de notre corps avec les choses" (MERLEAU-PONTY, 1945: 370). Mas o objecto traz a marca do homem e refere-se a um mundo que eu posso conhecer, embora me não possa nunca ser presente e sensível. E se, como disse Bergson, "reconhecer um objecto utilitário consiste fundamentalmente em saber servir-se dele" (DUFRENNE, 1953: 123), interpretar um objecto arqueológico é saber para que é que ele serviu.

A interpretação pode ser mais ou menos analítica, mais ou menos discursiva. Digamos que as coisas têm um coeficiente de opacidade, de adversidade, de resistência à interpretação e que, correlativamente, a interpretação tem um coeficiente de segurança, pode ser mais imediata ou mais analítica. Este muro que eu ponho a descoberto é uma muralha, não é muro de casa. Ninguém terá opinião diferente. É evidente para todos que se trata de uma muralha, porque é demasiadamente grossa para ser muro de casa. Esta estrutura é uma cista funerária: é evidente, porque contem ossos humanos. O ser da coisa revela-se ao mesmo tempo que os atributos da coisa. Mas podemos perceber os atributos sem perceber o ser da coisa. É o caso das fossas fumacentas de Binford, cuja interpretação foi um processo de análise que teve de passar pela exploração de relatos etno-históricos onde o autor encontrou casos análogos.

Há que aprofundar ou alargar, porém, o conceito de interpretação. A partir do que dissemos, quase poderíamos concluir que interpretar é definir a função prática dos objectos: a função daquelas fossas que serviram para enterrar prumos, a função daquelas tijoleiras que serviram de lareira. O homem, porém, não se limita a construir coisas práticas. O homem cria símbolos. Põe à porta um ramo de loureiro e sabemos que ali se encontra uma taberna. Chamaremos semiose ao 
processo segundo o qual qualquer coisa passa a desempenhar a função de signo (Morris, S. d.: 34). O torque de ouro que os Celtas usavam ao pescoço simbolizava a preeminência social do utilizador. Era, na expressão de Binford, um item sociotécnico. A expressão de item sociotécnico aplica-se a qualquer coisa que simboliza ou comunica o status social.

Os signos podem ser sinais ou símbolos. O sinal comunica uma ordem; o símbolo transmite um conhecimento ou representa materialmente uma ideia.

O monumento megalítico, para além de ter como função prática alojar os mortos, era um sinal, porque, implantado no espaço, afirmava a propriedade da terra; comunicava a outro grupo social uma ordem: a de que não podia ocupar aquele território, que já tinha dono.

No Lago Baringo (Quénia), Hodder observou a existência de três etnias, cada uma com seu tipo de brincos. Os brincos são um símbolo que transmite um conhecimento: qualquer indivíduo, cruzando-se com uma mulher, sabe pelos brincos a que etnia é que ela pertence (HODDER, 1982: 22).

$\mathrm{Na}$ Idade Média, a morte era representada por um esqueleto com uma roçadoira. O esqueleto é um símbolo que representa materialmente a ideia da morte.

A interpretação arqueológica é, para além da definição da utilidade ou funcionalidade das coisas, também uma leitura dos signos ou um desvendamento do seu significado. A leitura dos signos passa primeiro pela compreensão do ser da coisa como signo. Podemos, assim, dizer que interpretar é sempre desvendar o ser da coisa. Pode descobrir-se que o objecto é um objecto útil, e então o desvendamento do ser coincide com a identificação da sua função prática; mas se descobrirmos que o objecto é um signo, temos de prolongar a análise pelo exame do seu significado. Ora esta pesquisa de significado conduz-nos ao domínio das relações sociais, dos sentimentos e das ideias colectivas.

Em Çatal Hüyük, aplicadas às paredes internas das casas, encontram-se bossas mamiformes de argila, bossas que recobrem crânios de abutres cujo bico espreita no lugar do que seria o mamilo. As bossas representam seios, símbolos da mulher; e os crânios de abutres são símbolos da morte. A mulher e a morte são os referentes, aquilo de que se fala ou, neste caso, aquilo que se representa. Temos aqui um caso típico de interpretação: o ser do objecto foi definido como símbolo e 
procurámos depois o referente ou ideia simbolizada. Mas a interpretação não acaba aqui. A construção dos símbolos insere-se num determinado contexto. Porque é que a morte há-de ter sido representada pelo abutre e não por um esqueleto, como na Idade Média ocidental? Porque em Çatal Hüyük, possivelmente, os mortos eram expostos para serem comidos pelos abutres.

A análise, porém, pode ir ainda mais longe: a associação dos símbolos da mulher e da morte em Çatal Hüyük revelará o medo da mulher como portadora da morte. Mas a mulher é, por outro lado, representada, no mesmo povoado, em determinadas estatuetas de terracota dando à luz animais. Nestas terracotas revela-se a mulher como fonte da vida. A representação da mulher era portanto ambígua e os sentimentos do homem perante ela, contraditórios (HODDER, 1987 e 1990: 4-11).

A análise da dimensão simbólica dos objectos é um dos objectives da actual Arqueologia contextuai, que todavia assinala a impossibilidade de constituir um dicionário universal dos símbolos: ainda que os mesmo símbolos se possam encontrar em diferentes culturas, o seu significado varia consoante os contextos.

\section{A inferência}

A inferência arqueológica consiste em retirar, de um dado visível, um facto que se não pode presenciar directamente. Quando, da observação de uma coluna de fumo que sobe no horizonte, concluímos pela existência de uma fogueira ou incêndio que não presenciamos, estamos a fazer uma inferência. A inferência é, na expressão dos logicistas franceses, déduction du fait au fait.

A mais simples das inferências arqueológicas é a cronológica: se, levantando o pavimento de mosaico de uma casa romana, encontramos uma moeda cunhada em $250 \mathrm{~d}$. C., inferimos que aquele pavimento foi lançado depois de 250 d. C.; a moeda dá-nos um terminus post quem.

Para além das inferências cronológicas, há inferências que, à falta de melhor termo, chamaremos comportamentais: de um vestígio, inferimos um comportamento. Se, num povoado pré-histórico, encontramos foices e moinhos de vaivém, inferimos daí que os habitantes daquele povoado praticavam a cerealicultura; se, no mesmo ou noutro povoado, encontramos um molde para o fabrico de artefactos de metal,

Conimbriga, 34 (1995), 5-32 
inferimos que nesse povoado se praticava a metalurgia, coisa que se não pode inferir da simples presença de objectos de metal, porque estes poderiam ter sido adquiridos, por aquela população, noutro lugar ou a um mercador itinerante.

Nos dois casos, escolhidos pela sua extrema simplicidade, inferimos o que se não pode presenciar: os homens cultivando os campos, um artífice a fabricar um objecto de metal.

O dado visível ou do qual se parte é um testemunho e o dado inferido é um dado testemunhado. A correcção da inferência verifica-se quando o dado testemunhado é a única inferência possível do testemunho. Frequentemente, porém, deparamo-nos com várias inferências possíveis. Vejamos um caso:

"A destruição geral de um povoado como o Castro da Senhora da Guia... e a coincidência por toda a região de achados análogos de joias e outros depósitos (Serrazes, S. Pedro do Sul; Figueiredo das Donas, Vouzela; Baralhas e Vila Cova do Perrinho, Vale de Cambra) mais apelam a uma interpretação com base em movimentos de povos... para as mudanças ocorridas..." (SILVA, 1986: 36). Neste passo, o autor infere a existência de uma invasão a partir da destruição de um povoado e da ocultação de tesouros que terão sido enterrados na previsão do ataque. Mas será segura a inferência? Não poderá a destruição do castro ter sido um simples incêndio provocado por uma fogueira que algum habitante deixou inadvertidamente alastrar? Não poderão os tesouros explicar-se como ofertas votivas? A invasão pressuposta não é um facto seguramente inferido.

A observação dos pólenes, no Neolítico inglês (aqui não temos um artefacto, mas aquilo a que se convencionou chamar um ecofacto), revela, grosso modo, três fases: numa primeira, pólenes abundantes da floresta primitiva; numa segunda, redução desses pólenes; numa terceira, recuperação dos pólenes da floresta. Segundo alguns autores, a segunda fase corresponderia à desflorestação intensiva praticada pelos primeiros agricultores neolíticos e à abertura de grandes clareiras nas quais se praticava a cerealicultura; e a terceira, nos meados do $3 .^{\circ}$ milénio a.C., a uma involução da agricultura, que se poderia atribuir à erosão dos solos e à passagem de a economia mais baseada na pastoricia do que na agricultura. Mas esta interpretação foi recentemente contestada por Thomas (THOMAS, 1991: 25-27). A quebra do pólen das árvores pode não ser um fenómeno antropogenético, mas corresponder a um fenomeno natural, de que a peste do olmeiro (hoje 
demonstrada) é um caso; não temos, pois, que inferir, da quebra dos pólenes da floresta, a prática de uma agricultura intensiva e de uma grande desflorestação efectuada pelo homem. E da recuperação da floresta não temos que inferir uma passagem à pastoricia; talvez as unidades sociais fossem pequenas, cultivando reduzidas áreas cuja produção polínica dificilmente será visível.

Nestes casos em que os vestígios são passíveis de várias explicações, ou em que, a partir de um dado, podemos fazer várias inferências aceitáveis, como decidir sobre a inferência correcta? A verificação das inferências implica um processo de dedução ao qual já nos referiremos.

No caso da foice, dos moinhos de vaivém e do molde, temos objectos de função prática, que serviam para alguma coisa; sendo meios técnicos de produção, parece legítimo inferir a existência da produção a que eles serviram. Os comportamentos que deles inferimos situam-se ao nível da angariação da subsistência ou da produção de objectos, isto é, ao nível da vida económica. Podemos, porém, inferir relações sociais, mentalidades, ideologias.

O caso já citado de Çatal Hüyük é um exemplo de como se podem alcançar ideias e sentimentos colectivos via interpretação/inferência, processos que, neste caso, estão intimamente ligados, muito embora interpretação e inferência sejam dois momentos logicamente distintos.

A análise que Hodder faz da decoração da cerâmica neolítica holandesa é também um caso de inferência que conduz ao desvendamento das relações sociais. A cerâmica designada de Trechterbeker tem uma decoração contrastiva: os motivos opõem-se; zonas de motivos horizontais contrapõem-se a zonas de motivos verticais. A esta cerâmica sucede-se o estilo chamado Protruding foot beaker, em que a decoração é aditiva: o mesmo motivo vai-se repetindo, do bordo para o fundo, em zonas que são como as parcelas iguais de urna soma. Da primeira decoração pode inferir-se a existência de uma sociedade com tensões entre grupos dominantes e dominados, entre séniores e jovens, entre homens e mulheres. Da segunda, uma sociedade em que os grupos sociais estavam mais abertos a receber no seu seio indivíduos provenientes de outros grupos (HODDER, 1982, a).

Como diz Charlotte Brysting Damm (1991: 45), “a cultura material é um meio excelente para expressar ideias de um modo subtil, mas eficaz". Na Dinamarca, na transição do Neolítico Antigo para o Médio, verifica-se uma selecção maior dos indivíduos com direito ao enterramento nos dólmenes de corredor: uma parte menor da população 
é agora enterrada nesse tipo de monumento. Podemos inferir daqui uma hierarquização crescente da sociedade. Junto dos monumentos megalíticos surgem, porém, sepulturas individuais em simples fossas, donde se pode inferir "um silencioso protesto contra o direito restringido de enterramento em sepulturas monumentais".

Em conclusão: a inferência, isto é, a dedução de factos não presenciáveis a partir de dados observáveis é um raciocínio básico da Arqueologia, que constantemente se pergunta: o que é que este dado implica? Mas se, nalguns casos, a inferência é segura, noutros é mais problemática. $\mathrm{O}$ espectro da incerteza anda sempre a rondar as inferências arqueológicas. Como demonstrar a veracidade? Binford diria: através do método hipotético-dedutivo. Isto é: o facto inferido, que é um facto hipotético, deve implicar outros factos (para além daquele que constituiu a base da inferência). Devemos, pois, deduzir ou predizer o maior número possível de factos que a hipótese implica e verificar se eles se observam. No caso da invasão que Armando Coelho F. da Silva inferiu do incêndio do castro da Senhora da Guia e do ocultamento de tesouros, se a inferência é correcta, isto é, se houve invasão, deviam verificar-se incêndios e destruições noutros lugares. Digamos, entre parênteses, que isso ainda se não observou, pelo que a inferência, se não incorrecta, é pelo menos improvada. Se da foice inferirmos a cerealicultura, a prática desta tem de ser confirmada por outros factos independentes, como, por exemplo, o achado de grãos carbonizados, a observação de espectros polínicos que confirmem a desflorestação, a existência de machados que serviam para abrir, na floresta, os campos de cultivo, etc.

\section{A classificação}

A classificação, isto é, a integração dos objectos em classes, é um processo de aprofundamento do conhecimento, porque implica a formulação de juízes de semelhança e de diferença, inicialmente não contidos na percepção dos objectos. As classes que o arqueólogo utiliza são tipos e culturas.

Os objectos são indivíduos; mas entre os indivíduos pode haver similitudes, cujo reconhecimento conduz à formulação de tipos. Um tipo é um conceito, um modelo, ao qual vários indivíduos se conformam. Uma das funções do arqueólogo é classificar os seus objectos 
individuais numa tipologia existente. O investigador de ânforas romanas procurará classificar as suas peças na tipologia de Dressel ou de Peacock e Williams (1986). E se porventura o arqueólogo encontra materiais que nunca ninguém tipificou, o seu cuidado será o de elaborar uma tipologia própria para os seus objectos, como o fez, por exemplo, Susana Oliveira Jorge (1986: 672 e fig. 8).

Se os tipos são, ou não, émicos (usando a expressão inventada por Keneth Pike em 1954), isto é, se correspondem, ou não, aos arquétipos que tinha na mente o artífice que fabricou as peças ou a população que as utilizou, talvez não seja muito importante, tendo em vista os fins a que a nossa tipologia se destina, fins que já discutiremos (HAYDEN, 1984). Este problema de saber se os tipos são émicos, posto nos meados do século, deu origem a uma controvérsia que os norte-americanos apelidaram de the typological debate e que ainda se não extinguiu. Não há, talvez, meio de demonstrar a emicidade dos nossos tipos e possivelmente muitas tipologías são um misto de categorias émicas e éticas, estas apenas com sentido para nós, isto é, apenas heurísticas. Mas, conforme afirmou A. Spaulding já em 1953, a classificação deveria ser, idealmente, "um processo de descoberta de combinações de atributos preferidos pelos fabricantes dos artefactos e não um processo arbitrário do classificador".

O tipo é definido por atributos ou é uma combinação de atributos: matéria, forma, dimensão, peso ou volume, etc. Deve ter coerência interna e isolamento exterior (ADAMS e ADAMS, 1991: 71). Existe coerência interna quando os atributos formam um conjunto relacional e existe relação de atributos quando a modificação de um implica a modificação de outro. Um tipo, que tem uma certa forma, deve ser fabricado sempre na mesma matéria; se a matéria muda, teremos outro tipo. Para além da coerência interna, o tipo deve ter isolamento externo, isto é, deve definir-se de tal forma que possa distinguir-se claramente de outro tipo. É importante definir com tal clareza os tipos que dois arqueólogos, tendo de classificar a mesma peça, encontrada numa escavação, e servindo-se da nossa tipologia, possam ambos integrá-la no mesmo tipo sem divergências nem hesitações.

Forma, matéria, dimensão, função, estilo - parecem-nos os cinco parâmetros ou variáveis fundamentais da definição dos tipos, ou, para usar a expressão de Adams e Adams (1991: 30), os atributos diagnósticos do tipo («diagnostic attribute or diagnostic attribute cluster).

A forma é, para muitos tipologistas, a variável principal. A matéria foi, porém, a variável principal que utilizámos no nosso estudo 
A cerâmica comum local e regional de Conimbriga (Coimbra, 1974). O problema do tamanho é inevitável na constituição de uma tipologia. Podemos ter duas peças cerâmicas da mesma forma, mas uma com 500 e outra com $1.500 \mathrm{~cm}^{3}$ de capacidade. Deveremos fazer dois tipos? No caso vertente, diríamos que sim, porque tão grande diferença de capacidade deve corresponder a funções diferentes e a consideração das funções deverá entrar na definição dos tipos. Quanto ao estilo, sem entrarmos aqui numa discussão aprofundada do que deve entender-se por estilo, diremos que é tudo quanto se não pode explicar por utilidade prática. Dois potes da mesma matéria, forma e dimensões podem ser: um deles, liso; o outro, decorado. Falaremos então de dois estilos diferentes: a decoração é estilo, porque não acrescenta a utilidade prática do pote.

A tipologia é um instrumento para poder comunicar: os objectos saem às centenas ou aos milhares de uma escavação e não seria possível descrevê-los e ilustrá-los a todos. Mas é também um instrumento para poder raciocinar. Todo o arqueólogo sabe que tem de reduzir a multiplicidade dos objectos à unidade dos tipos antes de poder fazer comparações, elaborar estatísticas, traçar origens, determinar cronologias. A tipologia é um passo para determinar onde e quando é que o objecto foi feito. Só depois de termos definido um tipo é que podemos pôr o problema da sua origem geográfica e solucionar o da sua cronologia, através da pesquisa de exemplares encontrados em contextos datáveis. O problema da origem e o problema da tecnologia do fabrico dos objectos também só podem ser resolvidos, na prática, mediante tipologías: sendo inviável a análise laboratorial de todos os objectos, temos de reduzi-los a uma classe, seleccionar objectos representativos da classe, analisar essas amostras e extrapolar os resultados para o conjunto dos indivíduos que fazem parte da classe. O problema da função também passa pela formulação de uma tipologia. Que transportavam estas ânforas romanas? Não podemos determiná-lo na maioria dos casos individuais. Mas se reduzirmos a diversidade dos objectos à unidade do tipo, encontraremos alguns indivíduos cuja função será determinada por inscrições pintadas ou por restos do conteúdo, e da função do tipo poderemos deduzir a função do indivíduo.

A formulação de tipologías é uma maneira de representar a cultura material, isto é, de traduzir a multiplicidade dos itens concretos em conceitos abrangentes. Ora, passada esta fase, o que o arqueólogo verifica é que os mesmos tipos aparecem regularmente associados em 
vários sítios, num largo espaço geográfico e que, noutro espaço, ao mesmo tempo, aparecem outros tipos, eles mesmo regularmente associados; ou que, no mesmo espaço, mas em épocas diferentes, aparecem conjuntos tipológicos divergentes. E esta verificação que conduz à formulação de culturas. A cultura é, para o arqueólogo, um conjunto de tipos que, entre determinadas balizas cronológicas e em específicas áreas geográficas, se encontram regularmente associados (CHILDE, 1961: 17 e 20 e CHILDE, 1969, 140).

David Clarke (1984: 220) reformulou o conceito de cultura, definindo esta entidade como série compreensiva e politética de tipos sistemática e concomitantemente presentes nos conjuntos arqueológicos de uma área geográfica limitada.

A cultura é uma série compreensiva, isto é, tem de englobar tipos representativos de várias actividades do sistema sociocultural. Não podemos definir uma cultura, por exemplo, só pela cerâmica, embora esta categoria de itens seja já pluri-específica, porque há cerâmicas de cozinha, de mesa, de armazenamento, funerárias e votivas: a cerâmica é portanto já de si representativa de várias actividades. Há, porém, que incluir, entre os tipos diagnósticos, outros que digam respeito a outras actividades, por exemplo, pesos de tear, que respeitam à tecelagem, alfaias agrícolas, que respeitam à lavoura, alfinetes e fíbulas, que respeitam ao vestuário, armas, que dizem respeito à caça e à guerra, etc. Há ainda que definir uma cultura por uma determinada forma de casa ou por uma determinada maneira de organizar o espaço doméstico, por um determinado tipo de enterramento (ou por tipos alternativos, porque o que às vezes se verifica é que uma cultura dispõe de formas de enterramento e de tipos de monumentos funerários diversos).

Ainda na definição de Clarke, o conjunto de tipos que define a cultura é um conjunto politético, isto é, nem todos os tipos que caracterizam a cultura se encontram em todas as estações que a integram.

O conceito de cultura é hoje muito atacado porque, na perspectiva dos atacantes, conduziu à definição de unidades estáticas, discretas e homogéneas. A cultura era definida por um conjunto de tipos materiais que não variava no tempo; por outras palavras, a cultura tinha um princípio e um fim, mas não uma evolução. As culturas tinham um quadro geográfico, para além de cujos limites haveria outras culturas; eram, por isso, unidades discretas, com fronteiras definidas. E toda a população usaria da mesma forma os mesmos itens, isto é, a cultura era

Conimbriga, 34 (1995), 5-32 
homogénea. Em segundo lugar, e isso também foi alvo de críticas, a cultura foi muitas vezes equacionada com a lingua e a etnia: duas culturas diferentes corresponderiam a etnias e línguas diferentes.

Talvez pudéssemos dizer que estas censuras que se fazem à Arqueologia histórico-culturalista não são inteiramente justas. A Arqueologia histórico-culturalista divide frequentemente a cultura em fases. Armando Coelho F. da Silva, por exemplo, divide a cultura castreja em três fases, I, II e III, e subdivide cada uma em dois períodos, A e B ( 1986: 33s.). O que, porém, poderemos dizer com mais justiça é que a Arqueologia histórico-culturalista investigava pouco ou mal as razões ou os factores da mudança, recorrendo em demasia à explicação dela pela existência de invasões ou emigrações. E o caso de Armando Coelho F. da Silva, que explica por invasões ou imigrações a passagem da fase IA a IB e desta a IIA. A Arqueologia contemporânea descobriu as razões internas da mudança, ou outras razões de mudança. Com efeito, valorizou as transformações ambientais e o crescimento demográfico como factores de mudança. A erosão dos solos, por exemplo, pode justificar a passagem de uma economia agrária a uma outra pastoril; e o crescimento demográfico, tornando insuficiente a produção, pode conduzir à guerra ou, alternativamente, ao desenvolvimento dos meios técnicos de produção, de modo a retirar mais alimentos das mesmas terras, ou ainda à especialização com incremento das trocas; nesta última alternativa, os sistemas sociopolíticos podem tornar-se mais complexos, surgindo chefes para organizarem as trocas e a redistribuição dos produtos.

Se a Nova Arqueologia explica a evolução sobretudo pelas transformações ambientais e pelo crescimento demográfico, a Arqueologia marxista encara as tensões sociais intra ou intergrupais como principal motor da mudança.

A visão estática das culturas, que se critica à Arqueologia histórico-culturalista, não é uma conotação necessária do conceito de cultura. Também o não é a discrição. Podemos usar operacionalmente o conceito de cultura admitindo interacções e distinguindo zonas centrais ou nucleares e franjas em que os tipos característicos de duas culturas se misturem. Em terceiro lugar, pela chamada de atenção para o carácter politético das culturas, Clarke superou o problema da homogeneidade sem abandonar o conceito de cultura. E por último, cultura não tem necessariamente que equacionar-se com etnia e língua (HoDDER, 1978: 3-24).

Conimbriga, 34 (1995), 5-32 
As críticas que têm sido dirigidas ao conceito de cultura, muitas delas pertinentes, a nosso ver não demonstraram ainda que o conceito não é hermeneuticamente válido nem propuseram outro mais válido que o substitua. Shennan, por exemplo (SHENNAN, 1978: 113-139), pretendeu demonstrar que o conceito mascara, mais do que desvenda, a realidade histórica; mas o que de facto provou, num ensaio aliás extremamente interessante de arqueologia quantitativa, foi que as culturas não são homogéneas. Para mais, escolheu um mau exemplo, o da cultura campaniforme, porque hoje ninguém atribui ao campaniforme o estatuto de cultura.

Shennan demonstrou apenas que, no interior de uma mesma cultura, diferentes áreas apresentam diferentes percentagens relativas dos mesmos itens; que pode haver variabilidade regional dentro de uma mesma cultura; que a cultura material pode ser diferentemente manipulada em diversas áreas; mas não demonstrou aquilo que pretendia provar: que a cultura é uma entidade insatisfatória. Ainda segundo Shennan, a definição das culturas como entidades politéticas, feita por Clarke, "aproximou-se mais da realidade mas ao mesmo tempo disfarçou algumas das dificuldades" (1978: 113). Não cremos que tenha disfarçado dificuldades; apenas chamou a atenção para o facto de diferentes populações, integráveis numa mesma cultura, não partilharem exactamente da mesma forma a cultura material que as identifica. Se escavarmos, numa cidade romana, uma domus, vivenda de gente rica, e uma insula, prédio de vizinhos de mais modestos recursos, encontraremos seguramente na primeira maior percentagem de sigillata relativamente à cerâmica comum do que na segunda. Concluiremos pela diversidade cultural dos habitantes da domus e da insula, ou apenas pela existência de níveis diferentes de riqueza?

A nossa posição relativamente à operacionalidade do conceito de cultura não significa que não aceitemos a necessidade de revisão de muitas das culturas que na primeira metade do séc. XX se definiram. O campaniforme é um exemplo de cultura inexistente. A cultura da cerâmica de Peterborough e a da Grooved ware são outros: a Grooved ware, afinal, não define uma cultura mas é apenas uma cerâmica usada em contextos festivos por uma população que, noutros contextos, usava cerâmica de Peterborough. Trata-se de "tradições cerâmicas paralelas específicas menos de regiões que de contextos" (THOMAS, 1991: 100).

Se, como pretendemos, o conceito de cultura mantem a sua operacionalidade ou valor heurístico, também é certo que os seus críticos não propuseram ainda outras unidades de análise mais válidas. 
Renfrew (1986: 1-18) introduziu o conceito de polity, uma palavra dificilmente traduzível, cujo melhor equivalente, em português, será o de unidade sociopolítica. Mas se este conceito se aplica às sociedades estatais e proto-estatais, não nos parece que possa aplicar-se, salvo, nalgumas raras excepções, às sociedades pré-estatais. A sua aplicação, pelo próprio Renfrew, às sociedades do Neolítico Recente de Wessex (RENFREW, 1973: 539-558) parece sedutora; mas a extensão do conceito a outros casos, tentada por outros autores numa obra colectiva dirigida pelo mesmo Renfrew (RENFREW e CHERRY, 1986), não nos parece inteiramente convincente.

Outro conceito proposto é o de horizonte. Este pode ser definido por uma determinada cerâmica (como quando falamos do horizonte da cerâmica impressa e incisa neolítica ou do horizonte do vaso campaniforme), por um determinado sistema produtor (como quando falamos da "economia de espectro amplo" ou da "revolução dos produtos secundários") ou por uma mentalidade (e agora, por exemplo, falamos de horizonte megalítico, em que o culto dos antepassados levou à edificação de monumentos funerários colectivos).

Para efeitos de análise, o horizonte é um quadro demasiadamente amplo, que carece de uma subdivisão. O horizonte enfatiza os contrastes no tempo. Mas é óbvio que, no mesmo horizonte, há contrastes no espaço: o horizonte megalítico alentejano não é idêntico ao horizonte megalítico de Entre Douro e Minho, e possivelmente no interior do Alentejo e do Entre Douro e Minho há contrastes que justificam a distinção de unidades de análise menores. Mas que unidades podem ser essas? Unidades geoformológicas, isto é, regiões naturais?

Unidades geomorfológicas, como, por exemplo, uma bacia hidrográfica, são unidades práticas de investigação. Mas adoptá-las, por razões teóricas, não releva de um certo determinismo geográfico? As barreiras geográficas não são um total impedimento aos contactos e unidades sociais primitivas observáveis não se compartimentam necessariamente por áreas naturais.

Poderemos tomar como unidades de análise as Siedlungenkammern, conceito alemão que os ingleses traduzem por settlement cells, isto é, núcleos ou áreas de povoamento denso, separados um dos outros por zonas desertas ou onde o povoamento é escasso? Se estes núcleos, separados por terras de ninguém, são visíveis nalgumas épocas ou áreas, como na Europa central, no Bronze Final (COLES e HARDING, 1979: 341), não parece que constituam um fenómeno frequentemente 
observável e uma solução praticável para a resolução do problema das entidades de análise.

Uma alternativa à Arqueologia das culturas talvez possa ser uma Arqueologia por configurações.

O historiador, como escreveu Ricoeur, extrai configurações das sucessões (RICOUER, 1981: 278). A configuração é um conjunto de factos ligados por um enredo, uma cadeia de factos com directriz, com um princípio, um desenrolar e um desfecho. A crise nacional de 1383-85 ou a Revolução Francesa são configurações.

$\mathrm{O}$ conceito de configuração é talvez adaptável à Arqueologia.

$\mathrm{Na}$ segunda metade do $3 .^{\circ}$ milénio a.C. surgem, em diversos pontos de Portugal, povoados de cumeada protegidos com muralhas, do tipo de Vila Nova de S. Pedro ou Zambujal. A emergência destes povoados coincide com a invenção do cobre.

Dada a diversidade da cultura material que nestes povoados se observa, é impossível integrá-los a todos numa única cultura. Não tem sentido falar da "cultura" dos povoados fortificados calcolíticos. Mas é legítimo fazer deles uma unidade de análise, tentar explicá-los por uma conjuntura (que seria de afrontamento social?), tentar explicar as razões desse mesmo afrontamento, verificar se o fenómeno material de emergência dos povoados coincide com o fenómeno social de aparecimento de chefias eventualmente estáveis, analisar se há transformações ao nível das estruturas de produção e da ideologia que se verifiquem contemporaneamente .

Também não podemos falar de uma cultura megalítica; mas é legítimo, num manual de Pré-história, falar em bloco do megalitismo como uma configuração, que se traduz, no plano material, pelas antas ou dólmenes e, no plano ideológico, por um culto dos antepassados que "parece ter tido por função ultrapassar simbolicamente a incapacidade em que uma tecnologia rudimentar se achava de superar as forças da natureza" (TRIGGER, 1989: 342) ou que "regulava a exploração da terra e dos recursos da floresta, evitando uma competição destruidora ao mesmo tempo que, por meios rituais, fundamentava a natureza progressivamente hierarquizada da sociedade" (KRISTIANSEN, 1984: 80).

A esta configuração caracterizada pelo culto dos antepassados e as sepulturas colectivas sucede, na Dinamarca, uma outra configuração definida, no plano material, pelas sepulturas individuais e, no plano económico, por uma vida essencialmente pastoril. A pastoricia prati- 
cava-se numa paisagem que os homens não percepcionavam como construída pelos antepassados: não era necessário desflorestar, despedregar os campos. A paisagem era natural, não era uma coisa que tivesse implicado a acção de gerações precedentes. Daí a ausência do culto dos antepassados. E os grupos eram pequenos, de três ou quatro famílias, autónomos, não hierarquizados.

A configuração, em Arqueologia, não implica o enredo a que Ricoeur se refere; é antes um facto multiplicado em diversos lugares, sensivelmente na mesma época, e que carece de uma explicação globalizante, abrangente, que se encontrará no campo sócio-económico ou ideológico. Configuar implica comparar, descobrir uma unidade de sentido em factos inicialmente avulsos. Configurar, para usarmos uma expressão de Susana Oliveira Jorge (in ALARCÃO, 1990, 188), exactamente aplicada à emergência dos povoados fortificados calcolíticos, configurar é procurar esse sistema subjacente à realidade arqueológica que poderá explicar porque é que as fortificações aparecem, a razão (ou razões) de ser da sua implantação, o teor geral das suas características arquitectónicas, etc., etc."

Ora, exactamente porque é a procura de um sistema subjacente, e este só se pode encontrar numa estrutura social e/ou ideológica, a Arqueologia por configurações não põe a tònica nos objectos, nos fósseis directores, como a Arqueologia por culturas. É necessário, porém, evitar que esta Arqueologia por configurações seja uma Arqueologia de instantâneos desligados; é necessário encadear as estruturas para produzir um discurso coerente. Discurso que não tem, como o discurso histórico, um enredo, mas desvenda um processo. Por enredo entendemos um encadeamento de actos com intenção e que conduzem a um desfecho e, por processo, um encadeamento de formações sócio-económicas ou, para usar um conceito marxista, de modos de produção. A dificuldade maior do arqueólogo reside em mostrar como uma formação conduz a outra.

\section{A explicação}

A explicação é uma resposta ao porquê e neste sentido distingue-se da interpretação, que é desvendamento do ser da coisa, e da inferência, que é dedução de um facto (ou de um comportamento) a partir de um dado visível.

Conimbriga,34 (1995), 5-32 
De certa forma, a inferência contém em si mesma uma explicação, mas uma explicação dos vestígios, não uma explicação dos comportamentos. Porquê esta foice neste local? A existência da foice permitemos inferir a prática da agricultura e esta explica a presença da foice. A existência do molde de fundição permite-nos falar da metalurgia e esta explica a presença do molde. Mas uma coisa são os vestígios e outra são os comportamentos, de que aqueles constituem os testemunhos. Porque é que se começaram a praticar a agricultura e a metalurgia? Serão os comportamentos explicáveis, ou apenas observáveis sem que se possam explicar?

Porque é que os índios da região dos Grandes Lagos começaram a utilizar itens de cobre no período arcaico?

A explicação parece simples: os índios descobriram o cobre e, como os objectos deste metal eram mais eficientes que os de pedra, passaram a fabricar instrumentos de metal. $\mathrm{Na}$ realidade, não parece haver vantagem na utilização do cobre: este tinha de ser procurado a grandes distâncias e implicava um complicado processo de fundição; os itens de cobre eram assim muito menos económicos que os de pedra e talvez não fossem muito mais eficientes. Poderemos dizer que tinham pelo menos a vantagem de serem mais duradouros. Mas na realidade não o eram, porque os itens de cobre eram enterrados com os seus proprietários quando estes morriam, isto é, rapidamente saíam da circulação. Assim, os instrumentos de cobre não se explicam por razões práticas. Os itens eram sociotécnicos, isto é, eram símbolos de status social. Usavam-se instrumentos de cobre porque eram raros e caros e não acessíveis a todos (BINFORD, 1972: 26-32).

No exemplo dado há simultaneamente uma interpretação e uma explicação. Há interpretação na medida em que os objectos de cobre são classificados de sociotécnicos e não tecnómicos, isto é, não utilitários. E há explicação porque se responde a um porquê. Porque é que se começaram a utilizar instrumentos de cobre? Porque os indivíduos socialmente superiores têm necessidade de manifestar, de tornar visível, de simbolizar o seu poder através de objectos raros ou, como lhes chamou Clark, symbols of excellence (1986).

Como se explica o incêndio do castro da Senhora da Guia e o ocultamento de jóias na Beira central? Porque (segundo Armando Coelho F. da Silva) houve uma invasão. A invasão é a explicação daqueles factos.

Estas explicações implicam ideias gerais: no primeiro caso, a ideia de que os chefes têm necessidade de simbolizar o poder por meio

Conimbriga, 34 (1995), 5-32 
de objectos raros e, no segundo, a ideia de que, em face de uma invasão, as pessoas ocultam as suas posses mais valiosas.

A estas ideias gerais que servem para explicar chamamos teorias. "Uma teoria, no sentido estricto do termo, é um conjunto de generalizações semelhantes a leis, usadas para explicar e predizer fenómenos empíricos. Contudo, existem poucas teorias nas ciências sociais (se é que existe alguma) e nelas o termo é geralmente usado no mesmo sentido de modelo" (SEYMOUR-SMITH, 1986 s.v. theory). E, relativamente a modelo, diz a mesma autora que "um modelo procura explicar as relações entre um conjunto de fenómenos específicos ou de variáveis por meio de uma representação dessas variáveis numa forma simplificada". Lalande define teoria como "ampla síntese que se propõe explicar um grande número de factos e admitida, como hipótese verosímil, pela maior parte dos investigadores de uma época" (LALANDE, 1972, s.v. théorie). A teoria serve, portanto, para explicar.

As ideias de que o crescimento demográfico e as alterações ambientais conduzem a transformações culturais, ideias centrais ao funcionalismo da Nova Arqueologia, são uma teoria. A ideia, desta vez marxista, de que as tensões sociais são inerentes a qualquer grupo social e que a mudança se explica pelo jogo dessas tensões, é também uma teoria. A tese de que a cultura material se explica por relações sociais e por ideias é ainda uma teoria, desta vez contextualista. A ideia de que a racionalidade económica explica os comportamentos rituais é uma teoria; a ideia contrária de que a exploração económica se pode explicar por rituais é também uma teoria.

Rappaport (citado por CLARKE, 1984: 124-125) examina os rituais dos Tsembaga da Nova Guiné e explica-os como mecanismos reguladores do ecossistema. Há períodos alternados de guerra e paz entre os Tsembaga. Os períodos de paz são caracterizados por um ritual de agradecimento aos antepassados, durante o qual se matam numerosos porcos. Esta matança ritual tem por função estabilizar o número de porcos que, de outro modo, multiplicando-se em excesso, destruiriam as hortas e causariam danos ao ambiente. Aqui, o ritual deriva de uma função reguladora do ecossistema.

Por outro lado, os Kalasha da índia, que vivem da criação de gado caprino, têm bodes em demasia. O comportamento parece irracional, porque o número de bodes é muito superior ao que seria necessário para cobrir as cabras. A explicação reside em que a riqueza se mede pelo número de bodes e não de cabras e no facto de serem ape-

Conimbriga, 34 (1995), 5-32 
nas os primeiros que se sacrificam em cerimónias religiosas (GRANT, 1991: 111).

A nosso ver, há uma teoria, explícita ou implícita, em toda a explicação dos comportamentos; mas também só há teorias neste domínio da explicação; no domínio da interpretação e da inferência pode haver perspectivas e pressupostos mas não teorias.

Mais radicais, Shanks e Tilley defendem que o estabelecimento dos factos implica já uma teoria. "Os factos são, assim, construções carregadas de uma teoria a que a resistência dos dados obriga"; ou: "os dados correspondem assim a uma apreensão teorética do real" (SHANKS e TILLEY, 1992: 111).

No mesmo sentido se pronuncia Neustupny (1993: 11) para quem é "facto indiscutível que a própria descrição depende da teoria".

Que teoria subjaz, porém, à minha interpretação deste objecto como machado? ou desta estrutura como cista funerária? ou, indo mais longe, que teoria está implicada na minha inferência de que os habitantes desta aldeia, onde se encontraram numerosos machados com intensivos sinais de uso, praticaram a desflorestação?

"Não há maneira, dizem ainda os mesmos autores, de escapar à interpretação" (SHANKS e TILLEY 1992: 105). Nisso concordamos, se definirmos interpretação como o desvendamento do ser da coisa. E admitimos mesmo que esse desvendamento pode ser um processo analítico no qual se pode introduzir o erro. Basta pensar, uma vez mais, nos smudge pits de B inford, primeiramente interpretados como fossas fumacentas para afugentar os mosquitos e depois como fumadoiros para curtir peles. Mas poderemos deduzir, do facto de tudo passar necessariamente por uma interpretação, que tudo implica também uma teoria?

O vício de Shanks e Tilley deriva do facto de não definirem o que entendem por teoria; a nosso ver confundem a historicidade da percepção e os pressupostos da inferência com teoria.

A percepção é historicamente situada. Duas épocas não vêem o mesmo objecto da mesma maneira. Basta pensar no que nos diria um arqueólogo de fins do séc. XIX de um machado neolítico e o que nos diz um arqueólogo, hoje, do mesmo objecto. Aquele diria: recolhi um machado de pedra polida, fracturado e incompleto. $\mathrm{O}$ arqueólogo de hoje dirá: recolhi um machado polido de anfibolito, de secção oval, com evidentes sinais de ter sido utilizado. $\mathrm{O}$ arqueólogo do séc. XX não pensava que era importante identificar o material de que era feito o 
machado, nem a secção obtida por um corte transversal ideal da peça, nem observar os traços de uso.

A observação dos temas de investigação em voga nos últimos anos relativamente às civilizações meso-americanas é um bom exemplo de como as nossas análises são historicamente condicionadas. Durante os anos de guerra do Vietnam, os arqueólogos norte-americanos preocuparam-se intensamente com os problemas da guerra nas sociedades da América central; concluída a guerra, este interesse diminuiu. Por outro lado, à medida que na sociedade norte-americana aumentava o interesse pelos problemas ambientais contemporâneos, aumentava também o interesse dos arqueólogos pelos problemas ecológicos das sociedades meso-americanas e o número de artigos publicados sobre este tema atingiu o seu máximo no ano em que os norte-americanos publicaram a sua Lei de protecção às espécies em vias de extinção (BINTLIFF, 1988: 11).

Se a percepção dos objectos e a natureza dos temas investigados é historicamente situada, a inferência assenta em pressupostos. Vejamos.

Num monte de ossos de animais encontrados num povoado identificamos $65 \%$ de ovicaprinos, $35 \%$ de suínos e nenhum bovino. Inferimos daqui que a população daquela aldeia criava só ovicaprinos e suínos, nessa proporção. A inferência pode parecer segura. $\mathrm{Na}$ realidade, não o é, porque assenta num pressuposto: a de que a lixeira é representativa dos gados criados. Mas será? Talvez aquela lixeira represente apenas a alimentação da gente mais pobre do povoado, que não criaria bovinos nem comeria a carne deles. Ou talvez os bovinos fosse criados, não para serem mortos pela carne, mas apenas para serem utilizados como força de trabalho. Neste caso, quando morriam, podiam ser enterrados noutro local, não na lixeira dos alimentos.

A análise que Hodder faz da deposição dos lixos entre os Nubas (Sudão) revela que, por razões ideológicas, os ossos de suínos são lançados por aquelas gentes em lixeiras diferentes das dos ossos de bovinos (HODDER, 1982: 159). Assim, todas as inferências que se têm feito sobre a composição dos gados a partir dos ossos das lixeiras assentam num pressuposto: a de que as lixeiras representam a composição real dos gados criados.

Um pressuposto não é uma teoria; um pressuposto é um juízo que se forma sem se ter jamais pensado na possibilidade do juízo contraditório (GOBLOT, 1947: 167) e serve para inferir; a teoria é uma ideia geral semelhante a uma lei e serve para explicar.

Conimbriga, 34 (1995), 5-32 
A explicação é a última palavra do arqueólogo e ela envolve, como acabámos de ver, a teoria. Seria talvez o momento oportuno para examinar as três grandes teorias gerais que hoje se oferecem ao arqueólogo: a funcionalista, a marxista e a contextualista. Serão elas mutuamente excluíveis ou compatíveis? Terá chegado o momento de, dialécticamente, estabelecer a unidade numa Arqueologia cognitiva/ /processual de que Renfrew e Bahn apontam os princípios (RENFREW e BAHN, 1991: 431)? Deixaremos para outra ocasião a análise deste problema.

\section{REFERÊNCIAS}

ADAMS, William Y. e ADAMS, Ernest W., 1991: Archaeological typology and practical reality. A dialectical approach to artifact classification and sorting, Cambridge.

AlarCÃO, Jorge de, 1990: Portugal. Das origens à romanização (= Nova História de Portugal), Lisboa.

BINFORD, Lewis R., 1972: An archaeological perspective, New York.

BINTLIFF, John, 1988: "A review of contemporary perspectives on the "meaning" of the past", in BINTLIFF, J. (ed.) Extracting meaning from the past, Oxford, p. 3-36.

CHILDE, V. G., 1961: Introdução à Arqueologia, Lisboa.

CHILDE, V. G., 1969: Para uma recuperação do passado, Lisboa.

CLARK, Grahame, 1986: Symbols of excellence, Cambridge.

CLARKE, David, 1984: Arqueologia analítica, Barcelona.

COLES, J. M. e HARDING, A. F., 1979: The Bronze Age in Europe, Londres.

COURBIN, Paul, 1982: Quest-ce que Varchéologie, Paris.

DAMM, Charlotte Brysting, 1991: "Burying the past: an example of social transformation in the Danish Neolithic", in GARWOOD, (ed), 1991: p. 43-49.

DUfRENNE, Mikel, 1953: Phénoménologie de la perception esthétique, I, Paris.

DUNNELL, Robert C., 1980: “Americanist archaeology: the 1979 contribution", American Journal of Archaeology, 84(4), p. 463-478.

FLANNERY, Kent, 1993: "Archaeology with a capital S", in REDMAN, C. (ed.), Research and theory in current archaeology, New York.

GARWOOD, D. et alii, 1991: Sacred and profane, Oxford.

GOBLOT, Edmond, 1947: Traité de logique, Paris.

GRANT, Annie, 1991: "Economic or symbolic? Animals and ritual behaviour", in GARWOOD (ed.), 1991, p. 109-114.

HAYDEN, Biran, 1984: “Are ernie types relevant to archaeology", Ethnohistory, 31(2), p. 79-92.

HEMPEL, Carl, 1969: "A função de leis gerais em História", in GARDINER, Patrick (ed.), Teorias da História, Lisboa, p. 412-435.

Conimbriga, 34 (1995), 5-32 
HodDER, Ian, 1978: "Simple correlations between material culture and society: a review", in HODDER (ed.) The spatial organization of culture, Londres, p. 3-24.

HODDER, Ian, 1982: Symbols in action. Ethnoarchaelogical studies of material culture, Cambridge.

HODDER, Ian, 1982 a: "Sequences of structural change in Dutch Neolithic", in HODDER (ed.), Symbolic and structural archaeology, Cambridge, p. 162-177.

HodDER, Ian, 1987: "Contextual archaeology: an interpretation of Çatal Hüyük and a discussion of the origins of agriculture", Bulletin of the Institute of Archaeology, Londres, 24, p. 43-56.

HODDER, Ian, 1990: The domestication of Europe, Oxford.

HODDER, Ian, 1992: Theory and practice in Archaeology, Londres.

Jorge, Susana Oliveira, 1986: Povoados da Pré-história recente da região de Chaves -V.a P.a de Aguiar, Porto.

KRISTIANSEN, Kristian, 1984: "Ideology and material culture: an archaeological perspective", in SPRIGGS, Mathew, Marxist perspectives in archaeology, Cambridge.

LALANDE, André, 1972: Vocabulaire technique et critique de la Philosophie, Paris.

MERLEAU-PONTY, M. 1945: Phénoménologie de la perception, Paris.

MorRIS, Charles, s.d.: "Fundamentos da teoria dos signos", in NatTIEZ, J. J., Problemas e métodos da Semiologia, Lisboa, p. 31-41.

NEUSTUPNY, Evzen, 1993: Archaeological method, Cambridge, 1993.

PEACock, D. P. S. e Williams, D. F., 1986: Amphorae and the Roman economy. An introductory guide, Londres.

RENFREW, C., 1973: "Monuments, mobilization and social organization in Neolithic Wessex", in RENFREW (ed.), The explanation of culture change. Models in Prehistory, Londres, p. 539-558.

RENFREW, C. e BAHN, Paul, 1991: Archaeology. Theory, methods and practice, Londres.

RENFREW, C. e CHERRY, John F., 1986: Peer polity interaction and socio-political change. Cambridge, 1986.

RICOEUR, Paul, 1981 : Hermeneutics and the human sciences, Cambridge.

RICOEUR, Paul, 1986: Do texto à acção, Lisboa.

SARTRE, Jean-Paul, 1993: O Ser e o Nada, Lisboa.

SEYMOUR-SMith, Charlotte, 1986: Mac Millan Dictionary of Anthropology, Londres.

SHANKS, Michael e TILLEY, Christopher, 1992: Re-constructing archaeology. Theory and practice, Londres.

SHENNAN, S. J., 1978: "Archaeological cultures: an empirical investigation", in HODDER, I., The spatial organization of culture, Londres, p. 113-139.

Silva, Armando Coelho F. da, 1986: A cultura castreja do Noroeste de Portugal, Paços de Ferreira.

SPAULDING, A. 1953: "Statistical techniques for the discovery of artifact types", American Antiquity, 18(4), p. 305-313.

THOMAS, Julian, 1991: Rethinking the Neolithic, Cambridge.

TRIGGER, Bruce G., 1989: A history of archaeological thought, Cambridge.

Watson, Patty Jo; LeBlanC, Steven A.; ReDMAN, L., 1987: El método científico en Arqueologia, Madrid, 1987.

Conimbriga, 34 (1995), 5-32 